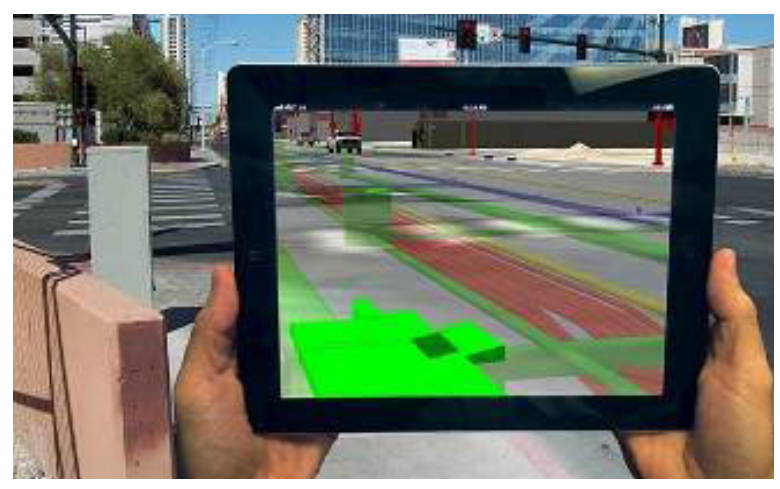

*Graduação em Tecnologia em Construção Civil pela Universidade Tecnológica Federal do Paraná (2002), graduação em Arquitetura e Urbanismo pela Pontifícia Universidade Católica do Paraná (2006), especialização em Engenharia em Edificações, Meio Ambiente e Saneamento pela Faculdade Anchieta de Ensino Superior do Paraná (2016) e especialização em Estruturas de Concreto: Ênfase em Projetos pelo Instituto de Educação Tecnológica De Luca Daher (2015).

\title{
Modelagem de Informação da Cidade (CIM) e suas potencialidades para gestão da manutenção urbana de Curitiba
}

\author{
City Information Modeling (CIM) and its potentialities for the urban
} maintenance of Curitiba

Tiago Rocha Lopes*

\section{Resumo}

Tecnologias de maior eficiência para planejamento e gestão urbana são de grande interesse para instituições e órgãos públicos. Diante desta tendência a Modelagem de Informação da Cidade (CIM) surge como sofisticada plataforma de trabalho, permitindo que profissionais colaborem em projetos e informações da cidade atraves de um modelo 3D paramétrico. Neste conceito definiu-se por uma pesquisa bibliográfica qualitativa, visando explorar a ferramenta, suas especificidades e os inovadores conceitos de parametrização, com foco nas potencialidades de aplicação no planejamento e gestão urbana de Curitiba. Verificou-se o potencial prático do CIM, através da estruturação de um modelo tridimensional organizado, alimentado em camadas e de forma colaborativa podendo se tornar agente centralizador de informações. $\mathrm{O}$ artigo contribui para o entendimento da tecnologia e suas possibilidades, que poderiam agregar ao planejamento de ações de intervenção urbana, o acesso a informações técnicas auxiliando em melhores análises quanto a potencialidades e interferências.

Palavras-chave: Tecnologias, modelagem, informação, paramétrico, colaborativa.

\section{Abstract}

More efficient technologies for urban planning and management are of great interest to public institutions and agencies. Facing this trend, City Information Modeling (CIM) appears as a sophisticated work platform, allowing professionals to collaborate on projects and information of the city through a parametric 3D model. In this concept it was defined by a qualitative bibliographical research, aiming to explore the tool, its specificities and the innovative concepts of parameterization, focusing on the potential of application in the urban planning and management of Curitiba. The practical potential of the CIM was verified through the structuring of an organized three-dimensional model, fed in layers and in a collaborative way and could become an information centralizing agent. The article contributes to the understanding of the technology and its possibilities, which could add to the planning of actions of urban intervention, access to technical information, aiding in better analyzes regarding potentialities and interferences.

Keywords: Technologies. Modeling. Information. parametric, collaborative. 


\section{Introdução}

Segundo projeções da ONU (2014), a porcentagem da população mundial que vive em áreas urbanas, avançará dos atuais $54 \%$ para $66 \%$ até o ano de 2050, apresentando crescentes desafios ao planejamento das cidades. Esta mesma tendência de crescimento de urbanização pode ser verificada no Brasil, onde segundo dados do IBGE a taxa de urbanização cresceu de forma constante até atingir 84,36\% no ano de 2010 conforme Figura 1.

\begin{tabular}{|c|c|}
\hline Período & Taxa de Urbanização \\
\hline 1940 & 31,24 \\
\hline 1950 & 36,16 \\
\hline 1960 & 44,67 \\
\hline 1970 & 55,92 \\
\hline 1980 & 67,59 \\
\hline 1991 & 75,59 \\
\hline 2000 & 81,23 \\
\hline 2007 & 83,48 \\
\hline 2010 & 84,36 \\
\hline
\end{tabular}

Figura1. Taxas de urbanização da população brasileira. Fonte: adaptado de IBGE, (2018)
Essas áreas urbanas podem ser definidas como áreas geográficas com concentração de aglomeração humana, caracterizadas pelas expressões de cada sociedade através de suas relações políticas, tecnológicas, econômicas e culturais.

De acordo com Ascher (2009, p.19):

A dinâmica da urbanização está ligada ao potencial de interação oferecido pelas cidades, à sua "urbanidade", ou seja a sua potência multiforme que gera o reagrupamento de uma grande quantidade de pessoas em um mesmo lugar.

Dentro deste conceito, o Urbanismo é a técnica de organização e intervenção destas relações em um ambiente que, seja pelas demandas crescentes ou por processos de melhoria qualitativa, está em constante transformação. Para o sucesso do processo urbanístico (planejamento, gestão e monitoramento), as ferramentas projetuais são de grande importância auxiliando uma constante busca por melhores resultados de forma colaborativa. 
Recentemente, o uso da modelagem 3D paramétrica, também chamado de Building Information Modeling (BIM), consolidou-se nas áreas de Arquitetura e Engenharia como importante ferramenta de modelagem, inserindo-se em um mercado que busca por eficiência e competitividade. Construído com tecnologias digitais, o modelo paramétrico trabalha de forma integrada pelas diversas disciplinas componentes a um projeto, resultando em um modelo virtual, preciso e capaz de dar suporte a construção, a fabricação e fornecimento de insumos para uma obra.

Na comunidade internacional, o BIM está sendo tratado com grande seriedade, devido ao seu potencial de precisão e gestão de projetos. Segundo reportagem internacional apresentada pela Constructible em 2018, o Reino Unido exige a adoção do sistema em projetos que utilizem recursos do Governo Central.

No Brasil, já é possível verificar estratégias de iniciativa pública como a contratação de projetos por parte dos Governos Federal e Estadual. Segundo o Portal BIM Paraná, o pioneirismo desse tipo de contratação por parte do Governo Federal ocorreu no ano de 2010, com o desenvolvimento de uma Biblioteca BIM, voltada para tipologias de edificações do programa habitacional Minha Casa Minha Vida. Na esfera pública estadual, a Companhia Paranaense de Energia (COPEL) foi precursora, realizando em 2012, a primeira licitação entre os estados brasileiros para os projetos do Centro de Operações utilizando o BIM.
Visando promover um melhor ambiente para investimento na tecnologia, o Governo Federal publicou o Decreto n 9377 de 17 de maio de 2018, que tem como finalidade coordenar a estruturação do setor público para adoção e contratações do sistema BIM.

O City Information Modeling (CIM) pode ser considerado como o equivalente ao BIM para a escala de cidade, cujas aplicações de análises de dados reais e informações georreferenciadas, interagindo com as equipes de trabalho dos diversos setores, têm o objetivo de promover a construção de um modelo comum para gestão urbanística.

Basicamente o conceito abordado na escala de cidade é de um agrupamento de dados através de um modelo 3D compreensível e capaz de ser acessado e utilizado em ações (pesquisas, inventários, análises e verificações de interferências) de diferentes setores e órgãos. Exemplificando, é possível simular e mapear no modelo, deslocamentos de fluxos de trânsito, densidades populacionais, posicionamento de infraestrutura, etc.

Podemos considerar o CIM como uma ferramenta indutora à categoria de Cidades Inteligentes, com significativo potencial de inserção no Planejamento Urbano. Sendo assim, a busca pelo conhecimento da ferramenta oportuniza o ganho de informações, contribuindo para eficiência nos processos de planejamento, controle e gestão urbana. Este artigo visa o entendimento da nova 
tecnologia e seus conceitos básicos (Informação, Paramétrica e Modelagem), do processo e sua importância para a cidade.

A pesquisa da plataforma CIM vem ao encontro aos conceitos de inovação, atributos esses pelos quais a cidade de Curitiba é notadamente reconhecida. $O$ objetivo geral é pesquisar e ampliar a discussão sobre o uso do CIM como ferramenta de planejamento e gestão urbana. Nessa perspectiva, os objetivos específicos desta pesquisa são: a) descrever o sistema CIM e seu funcionamento; b) diagnosticar metodologias de trabalho do sistema, potencialidades e sua aplicabilidade; c) elencar possíveis ferramentas que podem ser utilizadas na montagem de trabalhos CIM; d) identificar correlação entre as potencialidades do sistema CIM e Manutenção Urbana de Curitiba.

\section{Procedimentos metodológicos}

Conforme Lakatos e Marconi (2017), o método traça o caminho a ser seguido na busca de conhecimento, no qual a pesquisa bibliográfica, com base em livros, artigos científicos e revistas, auxilia na produção científica atualizada.

Dessa forma, a metodologia definiu-se por uma pesquisa qualitativa que visa explorar as causas atribuídas ao problema e o estudo de caso sobre o CIM como ferramenta de inovação, explorando suas especificidades e os inovadores conceitos de parametrização, com foco em suas potenciali- dades de aplicabilidade ao planejamento e gestão urbana de Curitiba.

Por meio de um inventário bibliográfico sobre o CIM, foram coletados dados teóricos e práticos sobre o tema em artigos no Brasil e no exterior, com posterior classificação em 3 subtemas (conceituação teórica, aplicação do sistema e resultados práticos). Paralelamente, identificaram-se plataformas com potencial utilização para montagem de um sistema de modelagem paramétrica urbana, fazendo uma leitura quanto a sua aplicabilidade a gestão de manutenção da cidade de Curitiba.

A estruturação do artigo remete a ideia de formatar uma ordem organizacional do tema proposto, fazendo com que a leitura explicite com clareza o funcionamento da tecnologia e quais seriam seus benefícios para o planejamento urbano.

\section{Tecnologia CIM \\ Conceituação teórica}

O assunto proposto é de grande correlação ao conceito de Smart Cities $^{1}$ por inserir soluções inovadoras de tecnologia a práticas urbanas, com o objetivo de auxiliar na resolução de problemas cotidianos e multidisciplinares das cidades.

Segundo Lima (2016, p.6) acredita-se que:

As técnicas de mensuração da forma urbana tem despertado crescente interesse, devido 
ao desenvolvimento de geotecnologias, ou seja, tecnologias da informação espacial. Nas escolas e nos escritórios de arquitetura e urbanismo, flagra-se cada vez maior utilização de Sistemas de Informação Geográfica (SIG, também conhecido como GIS, em inglês). Um SIG é "um sistema computacional capaz de arranjar, armazenar, manipular e exibir informação referenciada geograficamente" e mais ainda, de produzir informação com a sobreposição dos dados especializados. No entanto, embora venham sendo usadas para dar suporte ao planejamento baseado em dados, essas técnicas prestam-se mais para análise e visualização do que para sistematizar padrões urbanos e analisar os indicadores legais.

Por outro lado, o uso de programas de CAD (Computer Aided Design) - consolidado na prática e ensino da arquitetura - não parece suficiente para abordar adequadamente a complexidade do espaço urbano, visto que eles não têm a capacidade de gerir as informações espaciais necessárias para apoiar um plano urbanístico.

No campo de atuação de projetos e equipes de planejamento urbanístico, a associação entre os dois sistemas SIG e CAD é o que se busca por meio de um sistema propositivo único chamado CIM, uma vez que os dois anteriormente descritos, apesar de terem grande demanda e potencialidades no processo, ainda apresentam limitações quanto a sua interação e rápidas alterações.

O termo CIM como descrito anteriormente é o paralelo urbanístico ao sistema BIM que trabalha através de processos colaborativos e simultâneos entre as diversas disciplinas envolvidas no projeto, construção e gestão de uma edificação.

De acordo com Eastman (2008) o sistema BIM pode ser definido como uma tecnologia de modelagem e um conjunto associado de processos capaz de produzir, comunicar e analisar modelos de construção. Dentro desta conceituação os componentes de construção são objetos inteligentes que entendem sua função e que podem estar associados a atributos gráficos e de dados coordenados e não redundantes.

Buscando contribuir para estabelecimento de uma conceituação para o CIM, pode-se dizer que o City Information Modeling é uma plataforma altamente sofisticada que permite que arquitetos, planejadores e outros profissionais colaborem em projetos e informações de toda a cidade.

Segundo CORRÊA et al. (2015, p.11) acredita-se que:

[...] uma Modelagem da Informação da Cidade adequada permitirá a exploração da semântica envolvida para a aplicação do modelo a diversas análises e simulações. Neste contexto dois fatores são importantes:

- a aquisição de dados, principalmente relacionada à existência de uma rede de sensores que fornece informação em tempo real de aspectos chaves da cidade, como o estado do trânsito nas vias principais, a presença de vazamentos na rede de distribuição de água, 
sobrecarga na rede elétrica, ou mesmo o gerenciamento de uma rede elétrica do tipo smart grid, para acolher cidadãos que produzem energia maior do que o próprio consumo e o devolvem à rede;

- uma camada de processamento destes dados para transformá-los em informação e, assim, alimentar o modelo.

Entende-se assim que a partir da inserção de dados e análises a um modelo geométrico, o universo de possibilidades no campo da gestão, pesquisa e intervenção de atividades urbanas é ampliado, possibilitando aos profissionais dos mais diversos campos de atuação na infraestrutura da cidade se utilizar do modelo CIM.

\section{Conceituação prática}

Dentro de uma conceituação de Modelagem da Informação é fundamental um entendimento sobre o que caracteriza os conceitos fundamentais de modelagem, paramétrico e informação, sendo:

a) A modelagem 3D livre é simplesmente a representação através de geometria em um desenho volumétrico tridimensional, construído através de linhas e planos de simples alterações. Estes desenhos, uma vez dissociados uns dos outros não são capazes de nos informar nada sobre o elemento construtivo ao qual representam.

b) $\mathrm{Na}$ modelagem paramétrica os elementos construtivos são definidos através de parâme- tros pré-estabelecidos, nas quais dimensões e tipos de materiais são facilmente adaptáveis a superfícies e diversas formas de projetos. Estes elementos são especializados e tem uma função específica no desenho, permitindo alterações, mas sempre mantendo a natureza de seu objeto.

c) A informação é o dado aplicado ao volume representado no desenho, sendo elemento chave em uma conceituação paramétrica e é o motivo pelo qual se usa esta técnica. Mesclando a informação ao projeto é possível interagir no processo criativo entre diversos setores envolvidos, permitindo acesso a quantitativos, fluxos, especificações, volumes de materiais e suas geometrias.

Para efeito de exemplificação de como um modelo de cidade pode interagir com a informação, o governo municipal de Melbourne na Austrália disponibiliza em ambiente virtual um modelo da cidade (Figura 2), que representa as edificações existentes, aprovadas e em construção permitindo monitoramento e análises quanto às ocupações do espaço urbano. Na Figura 03, é apresentado o monitoramento do fluxo de pedestres medido por sensores localizados na cidade, mantendo-os mapeados diariamente com o fornecimento de dados e gráficos.

As representações desses dois modelos exemplificados são suficientes para que os projetistas 


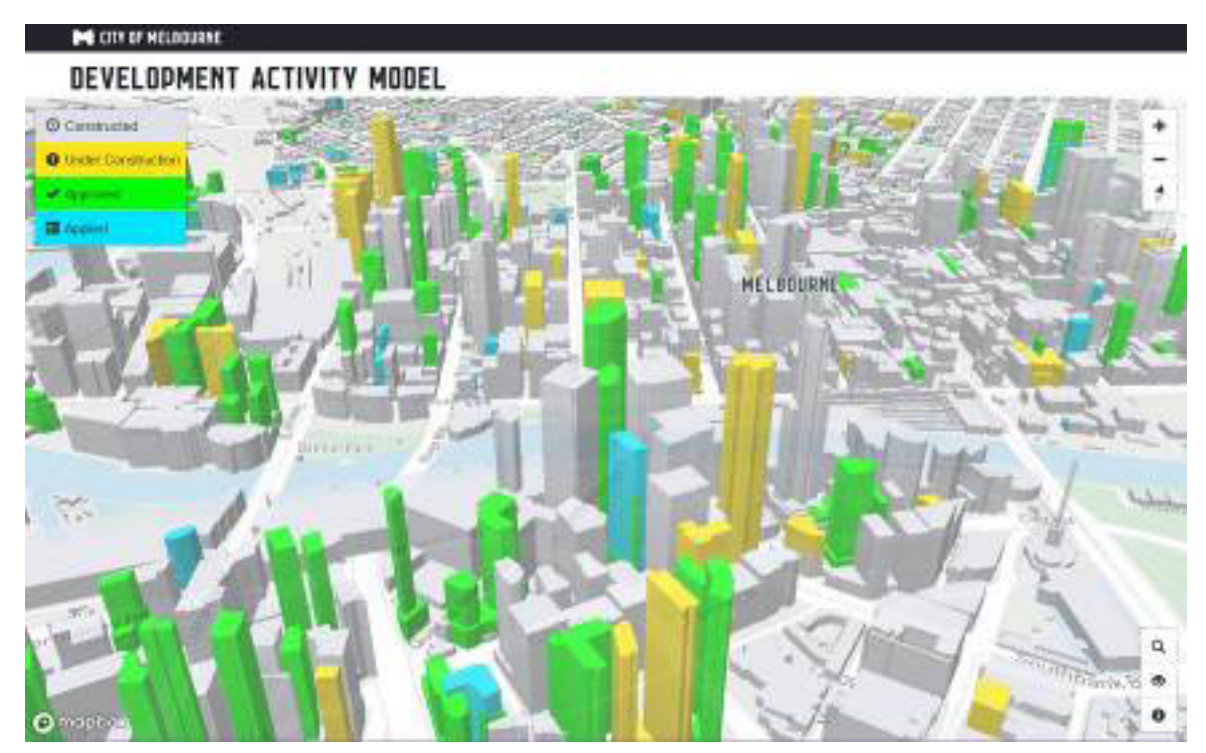

Figura 2. Representação da ocupação de melbourne relativa às edificações, permitindo análises da ocupação do espaço urbano.Fonte: City of Melbourne (2019).

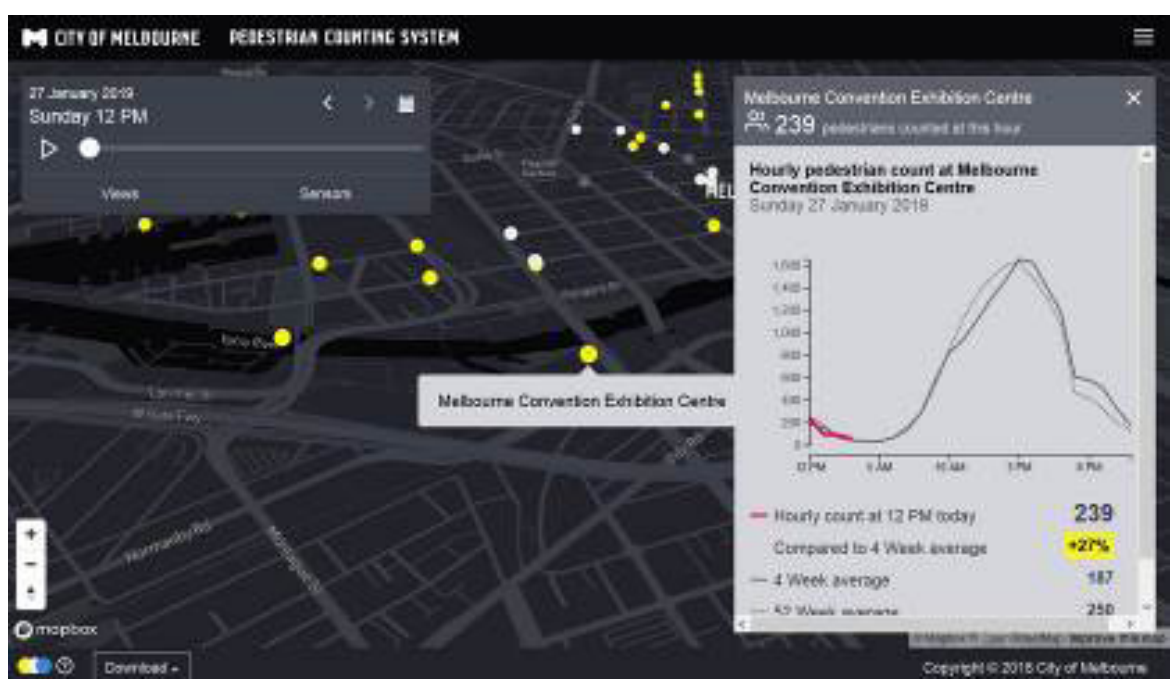

Figura 3. Fluxos de pessoas mapeados pelos sensores urbanos da cidade Melborne. Fonte: City of Melbourne (2019).

usjt • arq.urb • número 25 | maio - agosto de 2019 possam analisar e dimensionar fatores como necessidades de intervenções e melhorias em áreas de calçamento, transporte e iluminação pública em áreas mais adensadas e com maior fluxo de pedestres.

\section{Exemplos práticos}

No levantamento bibliográfico sobre aplicação de modelagem da informação em cidades, constataram-se três exemplos práticos considerados como inovações na área de CIM, descritos pela empresa de softwares Bentley (2011). Em dois estudos foram citadas as cidades de Helsinki na Finlândia e Montreal no Canadá que se destacaram na preocupação em manter equilíbrio entre crescimento e sustentabilidade planejada.

Helsinki considerada uma das pioneiras no assunto, desenvolveu seu primeiro modelo virtual no ano de 1987 e atualmente este modelo conta com cerca de 45000 edifícios e é utilizado para atividades de planejamento urbano, projetos de engenharia, gestão de licenças de construção, simulações de ruído, mapeamentos, simulações de tráfego, análises espaciais 3D e planejamentos de defesa civil. Esta abordagem propiciou uma vasta documentação de geometrias 3D, associadas às informações e documentações relacionadas a projetos da cidade. A proposta de planejamento envolve o uso de diferentes tipos de documentos, armazenados em servidores para colaboração de equipes de projetos e compartilhamentos de trabalhos. 


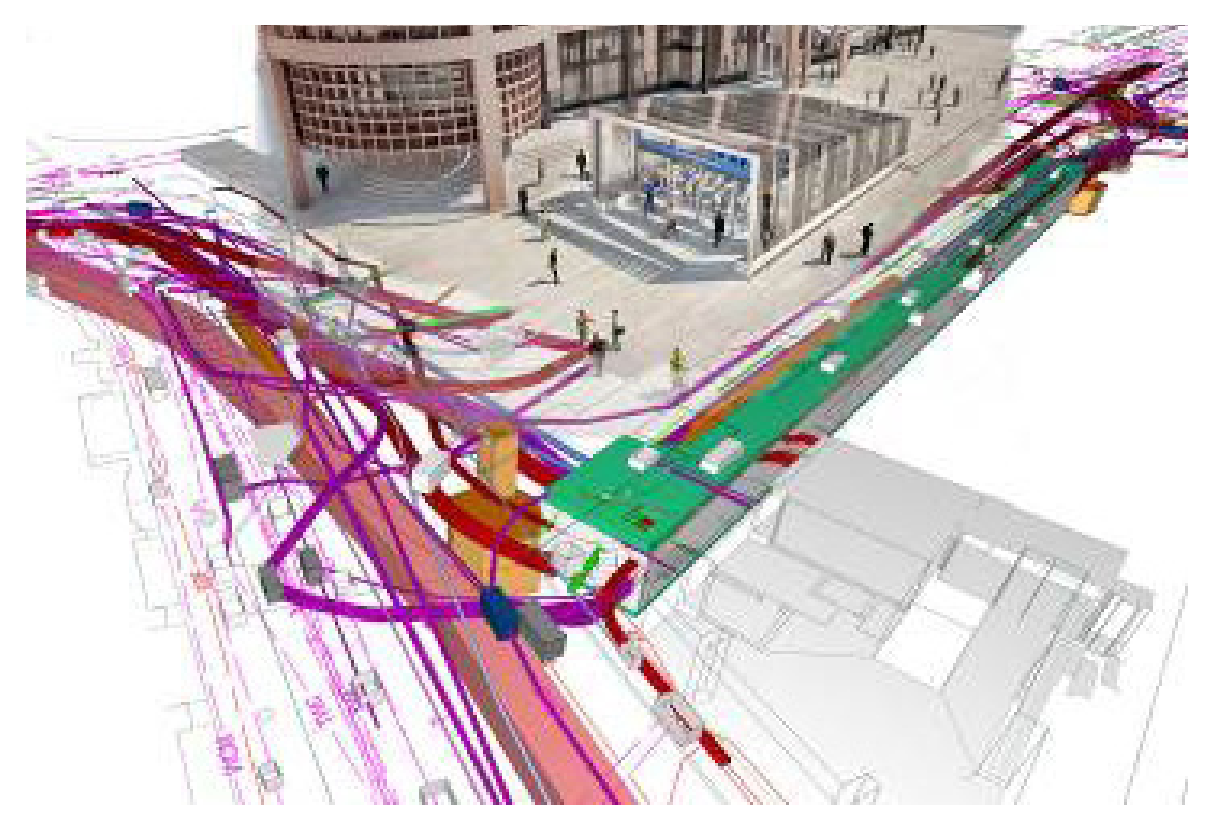

Figura 4. Infraestrutura urbana interagindo com estação do Crossrail de Londres. Fonte: Crossrail Londres (2019).

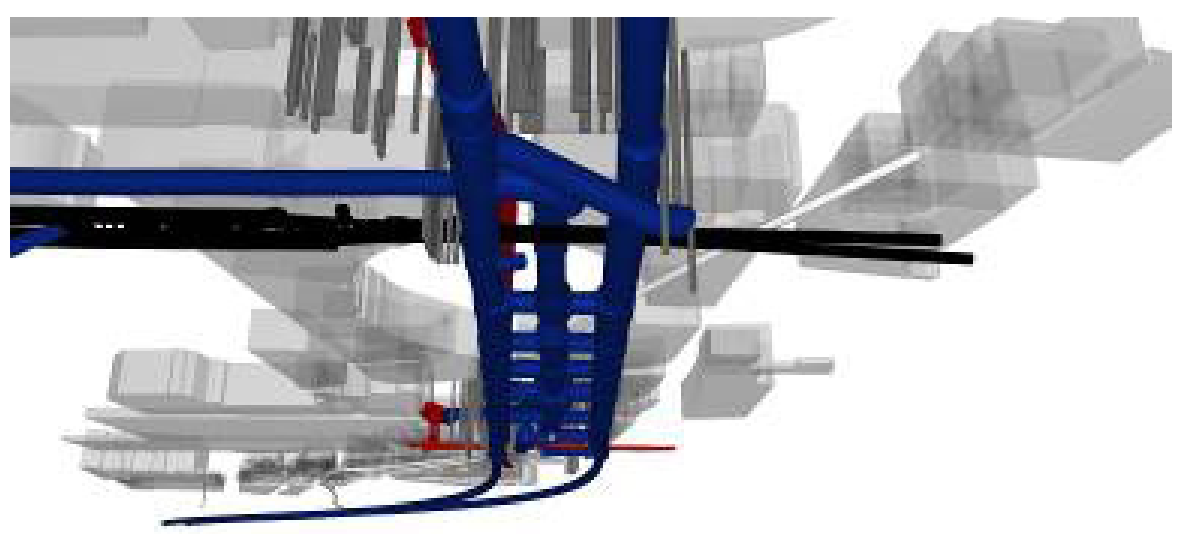

Fे:

Liverpool Street Station $\ominus \ominus \ominus \ominus \ominus$

Figura 5. Infraestrutura urbana interagindo com estação do Crossrail de Londres. Fonte: Crossrail Londres (2019).
Montreal assumiu uma posição de liderança no desenvolvimento de processos e uso de softwares para criação e gerenciamento de um modelo de cidade 3D preciso e inteligente. $\mathrm{Na}$ cidade, o departamento de engenharia geomática é o responsável por fornecer serviços de dados geoespaciais para os interessados em projetos de infraestrutura. De acordo com a Bentley, a cidade quer ampliar o acesso a informações para o público com seus modelos $3 \mathrm{D}$, incluindo características como objetos inteligentes e mapeamento de infraestruturas subterrâneas.

No terceiro estudo de caso, a Bentley descreve o trabalho do projeto do Crossrail ${ }^{2}$ de Londres, considerado como um dos maiores projetos de infraestrutura da Europa. Neste trabalho foi necessário um levantamento prévio, por intermédio de diversas técnicas combinadas para estabelecimento da infraestrutura existente acima e abaixo do solo, resultando em um modelo inicial de trabaIho. Esse modelo auxiliou no desenvolvimento do projeto devido a alta densidade de infraestrutura existente e a ser implantada.

O Crossrail, desde sua fundamentação de pesquisas, construiu uma estratégia impressionante de gerenciamento de dados, através de um projeto integrado (Figura 4 e 5), facilitando a colaboração multidisciplinar, tornando-se a base para um ativo sistema de gerenciamento.
2. Crossrail é um projeto Britânico para construir novas e importantes ligações ferroviárias a partir do centro de Londres. 


\begin{tabular}{|c|c|c|c|}
\hline Software & Função do Software & $\begin{array}{c}\text { Associação com outras } \\
\text { ferramentas }\end{array}$ & Potencialidade CIM \\
\hline City CAD & $\begin{array}{l}\text { Planejamento urbano através de } \\
\text { plataforma 3D paramétrica associando } \\
\text { desenhos e dados iniciais, quanto ao } \\
\text { esboço de ruas, zoneamentos de uso do } \\
\text { solo e densidades de edifícios. }\end{array}$ & $\begin{array}{l}\text { Pode ser trabalhado com Streetscape } \\
\text { que dimensiona e desenha perfis de } \\
\text { vias urbanas e o aplica ao modelo } 3 \mathrm{D} \\
\text { desenvolvido no CityCAD. }\end{array}$ & $\begin{array}{c}\text { Projeções de cenários uma vez } \\
\text { que ao se desenhar alterações } \\
\text { urbanas auxilia no redimensio- } \\
\text { namento de rotas, redesenho } \\
\text { de raios junto a meio fios, áreas } \\
\text { ocupadas, cálculo de habitações } \\
\text { e redimensionamento de blocos } \\
\text { urbanos. }\end{array}$ \\
\hline Eco tect & $\begin{array}{l}\text { Simulações de análise de eficiência } \\
\text { energética (radiação solar, iluminaçãa, } \\
\text { ventilação, acústica) e ambiental (som- } \\
\text { bras, reflexões, comportamento térmico) } \\
\text { de edificações e áreas urbanas. }\end{array}$ & $\begin{array}{l}\text { Adquirido pela Autodesk com a inten- } \\
\text { ção de suas ferramentas de análise } \\
\text { serem incorporadas ao software } \\
\text { Revit. }\end{array}$ & $\begin{array}{l}\text { Simulações de eficiência energé- } \\
\text { tica e sombras em edificações e } \\
\text { áreas urbanizadas. }\end{array}$ \\
\hline Insight & $\begin{array}{l}\text { Auxilia profissionais a projetarem edifí- } \\
\text { cios com maior eficiência em termos de } \\
\text { energia. }\end{array}$ & - Revit. & $\begin{array}{c}\text { Análises de eficiência energética } \\
\text { em edificações. }\end{array}$ \\
\hline Revit & $\begin{array}{l}\text { Permite o trabalho de forma multidisci- } \\
\text { plinar (arquitetura e projetos comple- } \\
\text { mentares), construindo um modelo } \\
\text { inteligente de edifício e infraestrutura } \\
\text { usado para planejar, projetar, construir e } \\
\text { gerenciar. }\end{array}$ & $\begin{array}{c}\text { - ECOTECT, Insight; } \\
\text { - Navisworks; } \\
\text { - Baseado em componentes paramé- } \\
\text { tricos permite o compartilhamento de } \\
\text { trabalho através do IFC }\end{array}$ & $\begin{array}{c}\text { Produção e análise de edifícios e } \\
\text { sua integração com a cidade, bem } \\
\text { como seus impactos dentro do } \\
\text { ambiente urbano. }\end{array}$ \\
\hline Navisworks & $\begin{array}{l}\text { Analise de modelos e dados integrados } \\
\text { durante a pré-construção para controlar } \\
\text { melhor os resultados do projeto. Per- } \\
\text { mite que usuários abram e combinem } \\
\text { modelos } 3 \mathrm{D} \text {, naveguem em tempo real e } \\
\text { façam revisões com ferramentas, incluin- } \\
\text { do comentários e medições. }\end{array}$ & - Revit. & $\begin{array}{l}\text { Interação entre edifícios e a cida- } \\
\text { de (edifícios públicos, estações de } \\
\text { transporte, edificações privadas } \\
\text { de interesse público, pontes, } \\
\text { trincheiras e viadutos dentre as } \\
\text { inúmeras outras possibilidades). }\end{array}$ \\
\hline Infra works & $\begin{array}{c}\text { Projetos de infraestrutura para cidades } \\
\text { e estradas com possíveis inserções de } \\
\text { funções do ARCGis }{ }^{4} \text { que nos apresenta } \\
\text { a associação do georreferenciamento ao } \\
\text { programa. }\end{array}$ & $\begin{array}{c}\text { - Civil 3D (detalhamento de infraes- } \\
\text { trutura.); } \\
\text { - BIM } 360 \text { (organizar, otimizar os } \\
\text { desenhos e informações elaborados } \\
\text { pela equipe). }\end{array}$ & $\begin{array}{c}\text { Formatação de modelo de infraes- } \\
\text { trutura da cidade. } \\
\text { Elaboração de cenários, estudos } \\
\text { de tráfego, associação ao geor- } \\
\text { referenciamento e a aspectos } \\
\text { organizacionais oferecidos pelo } \\
\text { BIM } 360 \text {. } \\
\end{array}$ \\
\hline Recap & $\begin{array}{l}\text { Converte com Scaners Laser realidade } \\
\text { em desenhos } 2 \mathrm{D} \text { e } 3 \mathrm{D} \text { (base para os } \\
\text { trabalhos nos demais propositivos). }\end{array}$ & Demais softwares Autodesk. & $\begin{array}{l}\text { Levantamento da estrutura } \\
\text { existente. }\end{array}$ \\
\hline
\end{tabular}

Figura 6. Plataformas que trabalham conceitos de parametrização. Fonte: adaptado de holistic city software (2018) e autodesk (2018)

3. Industry Foundation Classes, desenvolvido para criar um padrão universal de modelo de dados e representações permitindo que softwares de diferentes fabricantes possam intercambiar dados.
4. ARCGis é um sistema de informações geográficas que trabalha através de mapas interativos.

\section{Softwares/plataformas de trabalho}

O sistema CIM se apresenta como a solução para a construção de projetos inteligentes, possibilitando associar informações com a Internet das Coisas e trabalhar como agente participador de uma cidade inteligente. Pode-se dizer que a modelagem da informação nos transporta de um grupo de ferramentas que podem ser entendidas como mecanismos de desenho, para a utilização de verdadeiras ferramentas de projetos, com capacidades de análises e simulações de dados associados ao desenho.

Apesar do CIM ainda ser encontrado em bibliografias como assunto que habita campos conceituais, identificaram-se algumas referências de softwares e ferramentas que trabalham os conceitos de parametrização. Cada uma delas está identificada e descrita com informações quanto a suas funções, associações a outros softwares e possibilidades de aplicação (Figura 6).

Curiosamente, a Autodesk utiliza o termo BIM tanto para parametrização de edifícios e modelagem urbana. Na figura 7 , verifica-se a representação de um projeto de via urbana, com estudo de locação de caixas de drenagem e seus níveis de interferência para implantação de via, a partir do software Infraworks da Autodesk também citado como BIM cidades. 


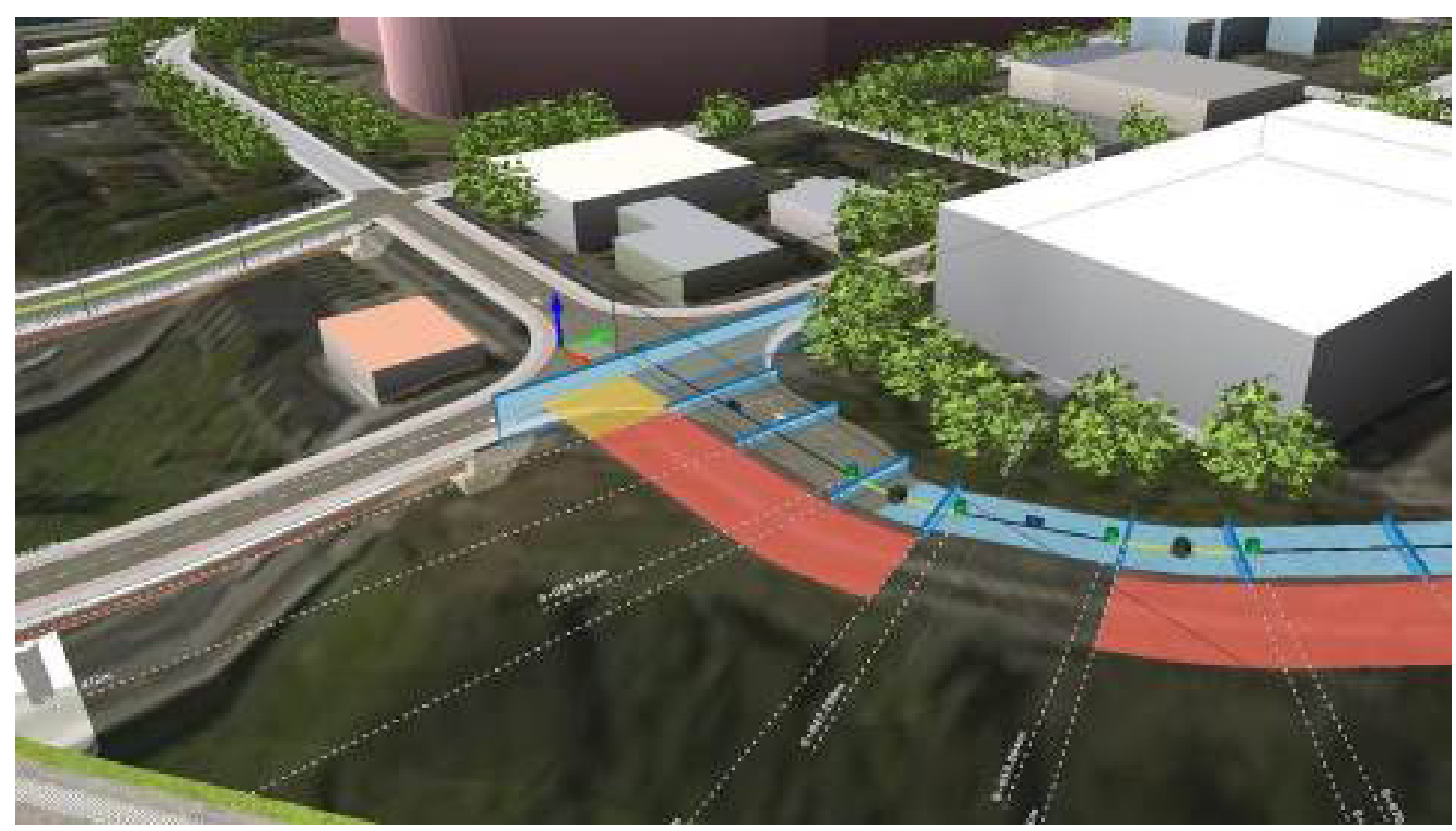

Figura 7. Representação de desenho paramétrico infraworks em uma via urbana. Fonte: Adaptado de <https://www.linkedin com/learning/infraworks-enhancing-and-optimizing-roads>, (2018).

Complementando as informações da Figura 6, segundo Amorin (2016) demais softwares auxiliam na construção de base de dados e equacionamento de outras necessidades, de acordo com sua especialidade como o CadnaA ${ }^{5}$ (análise de ruídos ambientais), Fluidyn PANACHE (poluição atmosférica), GABI (análise de fluxos de materiais de insumos e rejeitos), GOSOL (otimização de energia), VISSIM e MATSim ${ }^{6}$ que tratam de simulações quanto ao tráfego e sistemas de transporte.
Também cabe citar o grande portfólio de soluções para projetos de arquitetura e engenharia da empresa de softwares Bentley, baseados em conceitos de parametrização para uso em projetos de infraestrutura, incluindo edifícios, instalações industriais, estruturas offshore, redes de serviços públicos, comunicações, ferrovias, rodovias, pontes entre outros. Essas soluções de modelagem abrangem soluções de projetos, analíticas, construções, suportando a maioria das disciplinas,
Noise Abatement).

6. MATSim (Multi Agent Transport Simulation). 
incluindo arquitetura, mapeamento, topografia, engenharia civil, engenharia estrutural, engenharia de planta, análise hidráulica e hidrológica com processos de interação e colaboração de projetos fundamentados em um sistema de nuvem de projetos.

\section{Gestão de manutenção urbana na cidade de Curitiba}

A gestão da manutenção urbana na cidade de Curitiba está concentrada em um sistema hoje chamado de Sistema Integrado de Gestão da Manutenção Urbana (SIGMU), disponível para utilização das Secretarias Municipais responsáveis pelos serviços relacionados à manutenção da estrutura urbana. Estes serviços envolvem intervenções no sistema viário, parques, praças, edificações, limpeza pública e sistemas de drenagem. O Instituto das Cidades Inteligentes (ICl) define os conceitos quanto aos objetivos das ações de gestão da manutenção urbana:

Permite gerenciar as atividades de manutenção dos espaços e serviços públicos, oferecendo melhor planejamento, moderna administração, controle, economia de tempo e de recursos financeiros. Para o cidadão uma cidade mais limpa, organizada e bem administrada.

A solução de manutenção urbana apresenta módulos integrados e dinâmicos que oferecem para $\circ$ gestor público mais qualidade $e$ dinamismo para a tomada de ações estratégicas no município.
As principais funcionalidades apresentadas pelo SIGMU segundo o ICI são:

- Controle de acesso à solução por meio de usuário e senha, com gestão das permissões de acordo com as funcionalidades da solução;

- Visualização espacial em tempo real das solicitações de manutenção urbana registradas na solução, como pavimentação, paisagismo, limpeza pública, edificações e drenagem;

- Permite que o gestor obtenha informações em forma de gráficos, de acordo com a necessidade do usuário, bem como visualizar o quantitativo dos custos das manutenções;

- Realiza a troca de mensagens entre os usuários cadastrados na solução. Ação esta que facilita e agiliza o atendimento das ocorrências na ordem da manutenção urbana para o município em determinado período;

- Realiza o controle e registro dos custos de serviços executados no município, bem como da equipe de trabalho, veículos, equipamentos locados, entre outros.

Os principais benefícios desse sistema propiciam intervenções efetivas dos espaços públicos com agilidade e segurança aproximando os cidadãos aos órgãos públicos. As atividades e serviços prestados são alimentados diariamente, o que auxilia os órgãos gestores das atividades a dar respostas aos munícipes solicitantes e ao mesmo tempo criar um grande banco de dados das intervenções executadas na cidade. 
Paralelamente ao SIGMU, Curitiba conta com o Instituto de Pesquisa e Planejamento Urbano de Curitiba (IPPUC), que é o órgão municipal responsável pelo monitoramento, pesquisa e planejamento da cidade. Através do IPPUC usuários, munícipes e funcionários podem ter acesso a levantamentos e informações técnicas da cidade.

Quanto à manutenção urbana o IPPUC disponibiliza dados constantemente atualizados, arquivos digitais e mapas relevantes com acesso a informações quanto a arruamento, equipamentos públicos, ciclovias, altimetria, hidrografia, áreas ambientais, zoneamento e ocupações irregulares.

\section{Potencialidades do CIM para a gestão da ma- nutenção urbana}

De forma prática a manutenção urbana é responsável por obras emergenciais, preventivas e corretivas atendendo às diversas demandas urbanas, atuando em parceria com o cidadão que faz as solicitações via telefone no canal 156, internet e Administrações Regionais.

Avaliando o sistema CIM para Curitiba, pode-se observar que o grande potencial prático desta ferramenta seria a possibilidade de explorar os conceitos quanto a informar e acessar dados técnicos da infraestrutura.

A Prefeitura de Curitiba possui diversas e distintas camadas de informação produzidas por diferen- tes setores e órgãos segundo suas atribuições e atividades específicas diárias. Um modelo tridimensional organizado, alimentado de forma colaborativa poderia ser o agente centralizador de informações, permitindo melhor avaliação quanto a possíveis interferências, prevendo situações e proposições ajustadas à realidade.

Um modelo paramétrico poderia proporcionar aos órgãos envolvidos na manutenção da cidade, acessar e fornecer informações com destaque para as locações de infraestrutura de:

a) Tubulações e caixas de drenagem - Facilidade na consulta de desenhos, profundidades e localização auxiliando na correção de problemas emergenciais (erosões, entupimentos, análises quanto a possíveis melhorias e áreas de contribuição);

b) Empresas prestadoras de serviços (tubulações de água e esgoto, tubulações elétricas, gás e companhias telefônicas) - Otimização de ações tendo como base informações compatibilizadas, permitindo consulta a dados e planejamento de ações integradas;

c) Levantamentos e projetos de pavimentação - Elaboração de quantitativos mais precisos, diagnósticos de situação através do Autodesk Recap, que pode ser utilizado para definição correta da altura de fresagem e recapagem conforme patologias existentes. Análises inte- 


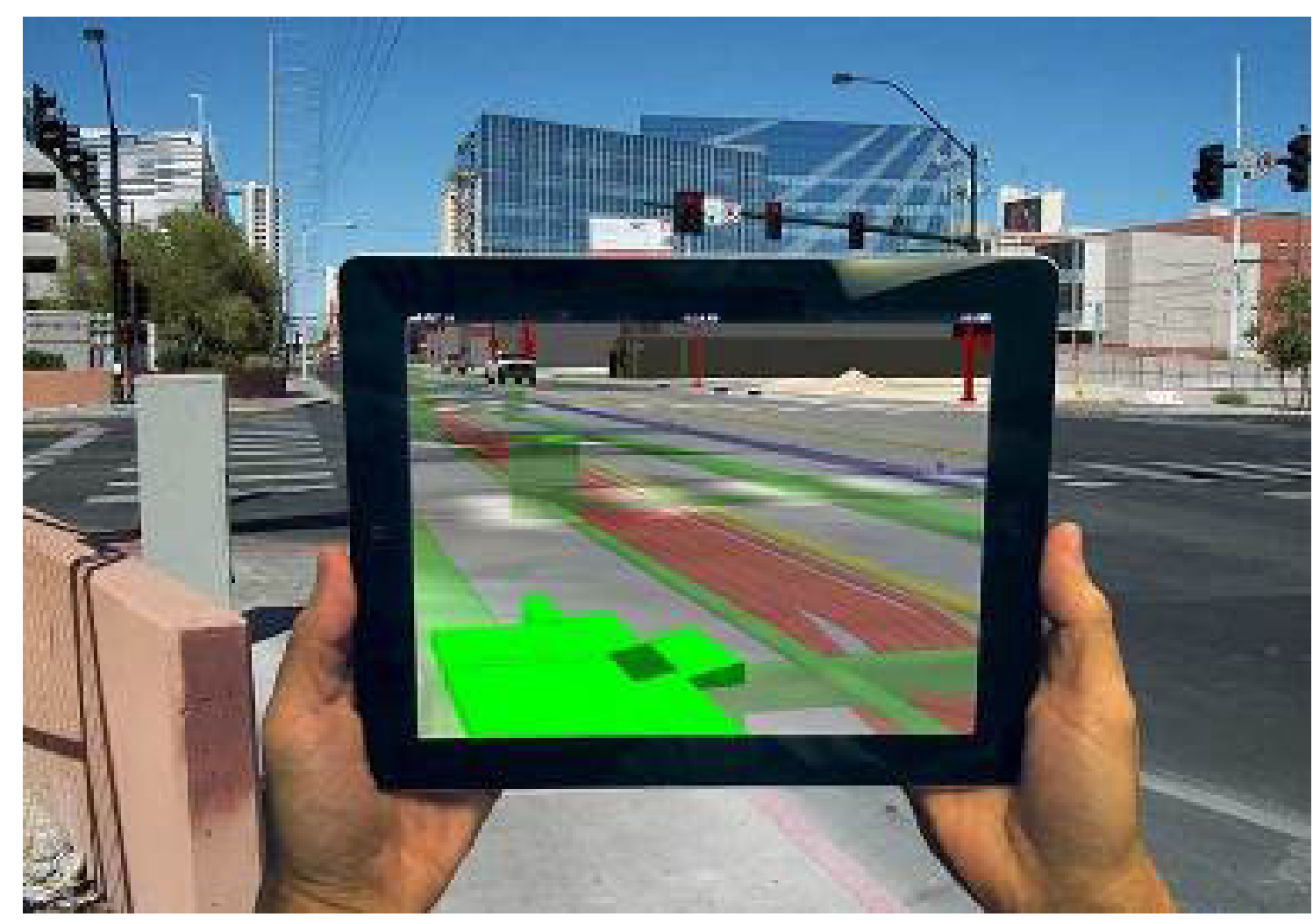

Figura 8. Representação de infraestrutura subterrânea sob o pavimento. Fonte: adaptado de geodatapoint, (2018). rativas de pavimentação e correções geométricas de vias associados aos demais agentes de interferência;

d) Estrutura de acessibilidade - Análises quanto a rotas acessíveis a equipamentos públicos e transportes;

e) Áreas verdes - Análises quanto a qualidade dos ambientes urbanos e manutenção periódica;

f) lluminação pública - Facilidade de acesso a especificações, análises de consumo, tipologia e quantitativos;

g) Sinalização e transito - Planejamento de ações para melhor fluidez no transito e simulações;

h) Edificações, modelos de zoneamento, ocupações urbanas - Elaboração de análises quanto a suas associações com o ambiente urbano e infraestrutura.

O acesso a informações pode se tornar um grande parceiro nas obras, auxiliando na previsão quanto aos locais de escavação, identificação e previsão de tipos de equipamentos a serem utilizados. Com a evolução tecnológica podem ser acessados até mesmo no local da intervenção, facilitando de sobremaneira o resultado prático de ações como pode ser observado na Figura 8. 
Além das potencialidades específicas já apresentadas, os softwares pesquisados podem auxiliar na elaboração de diagnósticos. O software ReCap, que utiliza scanners a laser para levantamentos de pavimentação e infraestruturas existentes, exemplifica positivamente as possibilidades de diagnosticar e levantar a infraestrutura com a tecnologia.

Vale mencionar que o sistema apresenta possibilidades no levantamento de quantitativos prévios para tomada de decisões, para obras e projetos, otimizando custos, estrutura e logística. Projetos com cortes e aterros, recapeamento de pavimentos e intervenções em bacias hidrográficas podem ser exploradas desde sua concepção até a fase de projeto executivo e orçamentos finais.

\section{Considerações Finais}

BIM e CIM confundem-se quanto às suas definições e aplicações, sendo que entre usuários e representantes de softwares podem-se encontrar ambos os termos.

De qualquer forma, a definição acaba sendo a busca pela parametrização de projetos volumétricos para o ambiente urbano.

Apesar de ainda não trabalhar com projetos BIM e CIM, a cidade de Curitiba apresenta grande volume atualizado de dados, projetos, levantamentos e diagnósticos que se encontram de forma descentralizada entre os setores. Pode-se apontar o grande cuidado da cidade na manutenção destas informações, o que a coloca em um momento prévio a parametrização, com necessidades de digitalização de dados existentes e levantamento de dados faltantes.

Quanto ao processo de gestão da manutenção urbana, o sistema CIM apresenta em suas ferramentas possibilidades que poderiam auxiliar de forma significativa o planejamento e previsão de custos de ações no município. $O$ acesso a determinadas informações de projetos de infraestrutura, tubulações e interferências poderiam orientar ações emergenciais e de reparos quando envolvem compatibilização entre Drenagem, Água, Esgoto, Tubulações Elétricas, Gás e companhias telefônicas.

Dentre as inúmeras possibilidades, a complexidade apresentada pelo sistema é a de gestão de informações envolvendo distintos órgãos, uma vez que os atores de intervenção na cidade são órgãos públicos e privados. Sendo assim, existe necessidade de verificação quanto à legalidade de atuação em um sistema CIM de interesse comum, que envolve relativos custos, acesso a informação, questões estratégicas e políticas envolvidas. Tecnicamente, diante do material pesquisado, o processo para desenvolvimento de um sistema CIM, consistiria na divisão do modelo em submódulos de interesse do município de Curitiba, que poderiam contemplar áreas como Edificações, Transportes, Módulo de Infraestrutura, Mobiliário Urbano, Rios Urbanos e Áreas Verdes. 
Cada um dos sub módulos necessitaria de um levantamento, modelagem paramétrica detalhada e respectivo georreferenciamento mediante um sistema SIG. A associação da modelagem paramétrica fiel (BASE BIM) e o sistema de georreferenciamento (SIG) resultaria no modelo CIM organizado em camadas e sem sobreposição de informações para a cidade como proposto no fluxo de trabalho proposto na Figura 9.

A grande dificuldade dessa proposta é o grande volume de trabalho para levantamento e digitalização de toda a cidade uma vez que o modelo deve ser fiel à realidade e conter dados de toda estrutura construída urbana. Portanto é um trabaIho que deve ser construído de forma colaborativa ao longo do tempo em um processo que pode ser minimizado com auxílio da tecnologia mediante scanners a laser 3D e seu georreferenciamento.

O sistema e seu funcionamento apresentam-se como grande desafio com inúmeras possibilidades para o planejamento e gerenciamento de atividades urbanas, integrando os setores de planejamento e gestão da cidade. Cabe ao poder público e aos setores privados, com interesse $o$ entendimento, tratarem de questões comuns solucionando as dificuldades operacionais e administrativas envolvidas.

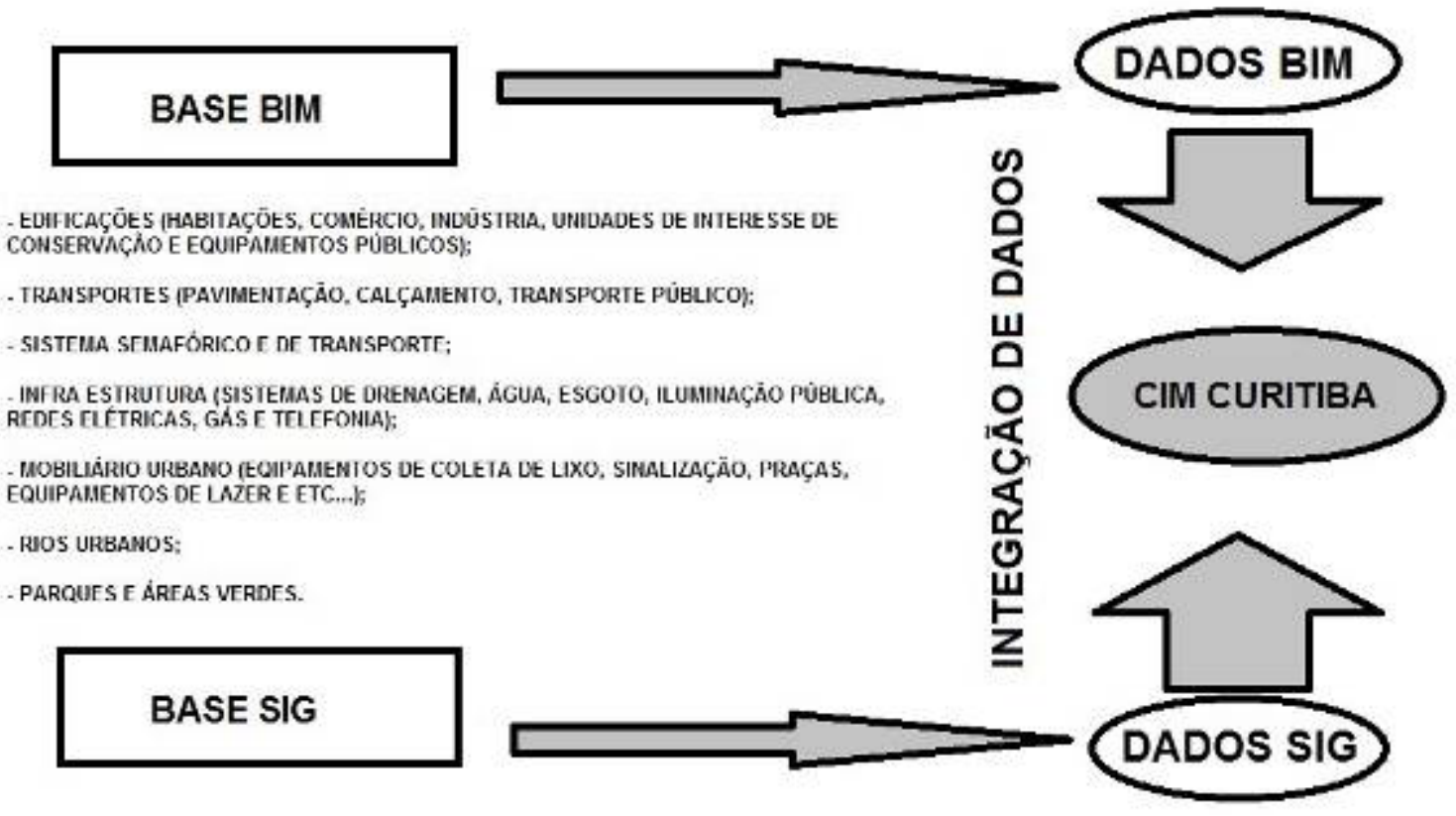

Figura 9. Fluxo de trabalho para montagem do CIM Curitiba. Fonte: Autor (2019). 


\section{Referências}

AECbytes. City Information Modeling. Disponível em <http://aecbytes.com/feature/2016/CitylnformationModeling.html> acessado em 04/09/2018.

ALMEIDA, Fernando; ANDRADE, Max. A Integração entre BIM e GIS como ferramenta de Gestão Urbana. Recife: VII Encontro de Informação e Comunicação na Construção, 2015.

AMORIN, Arivaldo; Cidades Inteligentes e City Information Modeling. Buenos Aires: SIGraDi, 2016.

AMORIN, Arivaldo; Discutindo o City Information Modeling (CIM) e conceitos correlatos. São Paulo: Gestão e tecnologia de projetos, 2015.

ASCHER, François. Os novos princípios do Urbanismo. São Paulo: Romano Guerra, 2010.

AUTODESK. Architecture, engineering \& construction collection. Disponível em: <https://www. autodesk.com.br/collections/architecture-engineering-construction/included-software $>$, acessado em 22/11/2018.

AUTODESK. Manual de implantação do piloto BIM. Disponível em: <http://static-dc.autodesk. net/content/dam/autodesk/www/campaigns/test-drive-bim-construction-br/download-workbook-now.pdf> acessado em 30/04/2018.
AUTODESK. Uma questão de um usuário sobre - Infraworks 360 - "Para o que realmente serve?". Disponível em <http://blogs.autodesk. com/mundoaec/sobre-o-infraworks-360/>, acessado em 28/11/2018.

BENTLEY. City Information Modeling for Sustaining Cities: Lessons learned from advanced users. Bentley: Case Study Showcase, 2011.

\section{CONSTRUCTIBLE. Next in BIM: City Information}

Modeling (CIM). Disponível em <https://constructible.trimble.com/construction-industry/next-in-bim-city-information-modeling-cim>, acessado em 05/12/2018.

CORRÊA, Fabiano; SANTOS, Eduardo. Na direção de uma modelagem de informação da cidade (CIM). Disponível em <http://www.proceedings.blucher.com.br/article-details/na-direo-de-uma-modelagem-da-informao-da-cidade-cim-20542> acessado em 23/04/2018.

CITY OF MELBOURNE. Development activity model. Disponível em: <https://developmentactivity.melbourne.vic.gov.au/>, acessado em 23/01/2019.

CITY OF MELBOURNE. Pedestrian counting system. Disponível em: <https://developmentactivity.melbourne.vic.gov.au/>, acessado em 23/01/2019. 
CROSSRAIL, Driving industry standards for design innovation on major infrastructure projects, 2019. Disponível em: <http://www.crossrail. co.uk/construction/building-information-modelling/>, acessado em 26/01/2019.

EASTMAN, Chuck; TEICHOLZ, Paul; SACKS, Rafael; LISTON, Kathleen. Manual de BIM: um guia de modelagem da informação da construção para arquitetos, engenheiros, gerentes, construtores e incorporadores. New Jersey: John Wiley and Sons, 2008.

FILHO, Zander Ribeiro Pereira; SERRA, Eduardo Gonçalves. BIM e a gestão integrada de Territórios Urbanos Sustentáveis: Um estudo sobre o planejamento urbano integrado e sustentável na cidade de Campos dos Goytacazes - RJ. Recife: VII Encontro de Informação e Comunicação na Construção, 2015.

FISCHER, Douglas. Why a Living 3D Model Is an Indispensable City Planning Tool. GEODATAPOINT, 2013. Disponível em: <https://www. pobonline.com/articles/100387-why-a-living-3d-model-is-an-indispensable-city-planning-tool>, acessado em 13/10/2018.

Geoespatial world. BIM for Smart Cities - Why is it a necessity? Disponível em <https://www.geospatialworld.net/blogs/bim-smart-cities/> acessado em 18/12/2018.
Governo do Estado do Paraná. Portal BIM Paraná. Disponível em <http://www.bim.pr.gov.br/ modules/conteudo/conteudo.php?conteudo=29> acessado em 23/01/2019.

Governo Federal. Decreto 9377/18, de 17 de maio de 2018. Disponível em <https://presrepublica.jusbrasil.com.br/legislacao/579674718/decreto-9377-18> acessado em 25/01/2019.

HOLISTIC CITY SOFTWARE, Technology for liveable cities. CITYCAD. Disponível em: <https:// www.holisticcity.co.uk/services/citycad/>, acessado em 15/11/2018.

HOMETEKA. BIM na construção de Cidades Inteligentes. <https://www.hometeka.com.br/ pro/bim-na-construcao-de-cidades-inteligentes/> acessado em 29/04/2018.

IBGE, Censo Demográfico 1940-2010. Disponível em <https://seriesestatisticas.ibge.gov.br/ series.aspx ?vcodigo $=$ POP122 $>$ acessado em 18/12/2018.

ICI, Manutenção Urbana. Disponível em <https:// www.ici.curitiba.org.br/conteudo/manutencao-urbana/75> acessado em 04/12/2018.

LAKATOS, E.M.; MARCONI, M. de A. Fundamentos de metodologia científica. 8. Ed. São Paulo: Atlas, 2017. 
LIMA, Mariana. Limites e possibilidades do city information modeling (CIM) em planejamento urbano. Disponível em <http://www.anparq.org. br/dvd-enanparq-4/SESSAO\%2014/S14-05-LIMA,\%20M.pdf> acessado em 30/04/2018.

MAXWELL, Lily. From BIM to CIM: why building and city information modelling are essential to the development of Smart Cities. Disponível em <https://www.bimcommunity.com/news/ load/917/from-bim-to-cim-why-building-and-city-information-modelling-are-essential-to-the-development-of-smart-cities>, acessado em 03/12/2018.
ONU, Relatório da ONU mostra população mundial cada vez mais urbanizada, mais de metade vive em zonas urbanizadas ao que se podem juntar 2,5 mil milhões em 2050. Disponível em $<$ https://www.unric.org/pt/actualidade/31537-relatorio-da-onu-mostra-populacao-mundial-cada-vez-mais-urbanizada-mais-de-metade-vive-em-zonas-urbanizadas-ao-que-se-podem-juntar-25-mil-milhoes-em-2050>, acessado em 18/12/2018.

SHARKEY, Linda. InfraWorks: Enhancing and Optimizing Roads, 2018. Disponível em: <https://www.linkedin.com/learning/infraworks-enhancing-and-optimizing-roads $>$, acessado em: 24/11/2018. 